\title{
Angioid streaks, clinical course, complications, and current therapeutic management
}

\author{
Ilias Georgalas' \\ Dimitris Papaconstantinou ${ }^{2}$ \\ Chrysanthi Koutsandrea ${ }^{2}$ \\ George Kalantzis ${ }^{2}$ \\ Dimitris Karagiannis ${ }^{2}$ \\ Gerasimos Georgopoulos ${ }^{2}$ \\ loannis Ladas ${ }^{2}$ \\ 'Department of Ophthalmology, \\ "G. Gennimatas" Hospital of Athens, \\ NHS, Athens, Greece; 'Department \\ of Ophthalmology, "G. Gennimatas" \\ Hospital of Athens, University \\ of Athens, Athens, Greece
}

\begin{abstract}
Angioid streaks are visible irregular crack-like dehiscences in Bruch's membrane that are associated with atrophic degeneration of the overlying retinal pigmented epithelium. Angioid streaks may be associated with pseudoxanthoma elasticum, Paget's disease, sickle-cell anemia, acromegaly, Ehlers-Danlos syndrome, and diabetes mellitus, but also appear in patients without any systemic disease. Patients with angioid streaks are generally asymptomatic, unless the lesions extend towards the foveola or develop complications such as traumatic Bruch's membrane rupture or macular choroidal neovascularization (CNV). The visual prognosis in patients with CNV secondary to angioid streaks if untreated, is poor and most treatment modalities, until recently, have failed to limit the devastating impact of CNV in central vision. However, it is likely that treatment with antivascular endothelial growth factor, especially in treatment-naive eyes to yield favorable results in the future and this has to be investigated in future studies.
\end{abstract}

Keywords: angioid streaks, pseudoxanthoma elasticum, choroidal neovascularization

\section{Introduction}

Angioid streaks were initially reported in 1889 by Doyne. ${ }^{1}$ They were described as "irregular radial lines spreading from the optic nerve head to the retinal periphery" in a patient who had retinal hemorrhages secondary to trauma. Knapp ${ }^{2}$ first coined the term "angioid streaks" in 1892 because their appearance suggested a vascular origin. Not until 1917 did Kofler $^{3}$ correctly determine that angioid streaks represented changes at the level of Bruch's membrane. Clinical examination with subsequent histopathological findings by Bock ${ }^{4}$ in 1938 in two patients with pseudoxanthoma elasticum confirmed that the underlying abnormality was not vascular in nature but rather a structural alteration in Bruch's membrane. A few years later similar histopathological results were found in patients suffering pseudoxanthoma elasticum, Paget's disease, but also from systemic diseases. ${ }^{5}$ Despite the fact that many systemic diseases like acromegaly, Ehlers-Danlos syndrome and diabetes mellitus, have been associated with angioid streaks, the most common diseases related to angioid streaks are pseudoxanthoma elasticum, ${ }^{6}$ Paget's disease ${ }^{7,8}$ of bone and sickle-cell ${ }^{9}$ anemia.

\section{Histopathological findings}

Angioid streaks represent visible irregular crack-like dehiscences in Bruch's membrane that are associated with atrophic degeneration of the overlying retinal pigmented epithelium (RPE). Histopathology in patients with angioid streaks that suffered from pseudoxanthoma elasticum demonstrated calcium deposition in Bruch's membrane which has several well demarcated breaks. ${ }^{10,11}$ In pseudoxanthoma elasticum, the primary lesion is the degeneration of elastic fibers of the connective tissue of the organism, while the calcium deposition represents a secondary disorder of unknown origin. ${ }^{11}$ In angioid streaks the elastic lamina that occupies the midsegment of Bruch's membrane is affected, resulting in disintegration and frying of the elastic fibers.
Correspondence: llias Georgalas

Consultant Vitreoretinal Surgeon,

59 Chrysanthemon str, P. Pshychico,

15452 Athens, Greece

$\mathrm{Tel}+302107768374$

Fax +302107768374

Email igeorgalas@yahoo.com 
Electron microscopy (EM) studies showed the presence of abundant granulomatous material in this lamina, a fact that supports the theory of pathologic elastic fibers' production.

In Paget's disease the bone deformities lead to calcium binding by the elastic fibers. ${ }^{12}$

For several years the appearance of angioid streaks in sickle-cell hemoglobinopathies was attributed to high level of serum iron. ${ }^{5,13,14}$ However, other types of anemias with increased iron levels in blood are not associated with angioid streaks. In addition, histochemical and EM studies, which took place in the eyes of patients with homozygotic sickle-cell anemia demonstrated severe tissue calcification; ${ }^{15}$ this fact favors the hypothesis that angioid streaks in patients with sickle-cell hemoglobinpathies are correlated to calcium deposition at Bruch's membrane.

Other histopathological findings include the break or absence of choriocapillaris beneath angioid streaks and thinning or decoloration of RPE; ${ }^{16}$ these changes are identical in angioid streaks despite different underlying systemic diseases.

\section{Ocular manifestations}

Angioid streaks are mainly asymptomatic. The appearance of symptoms occurs when the angioid streaks involve the foveola or in case of choroidal neovascularization (CNV) in the macular region (Figures 1,2).

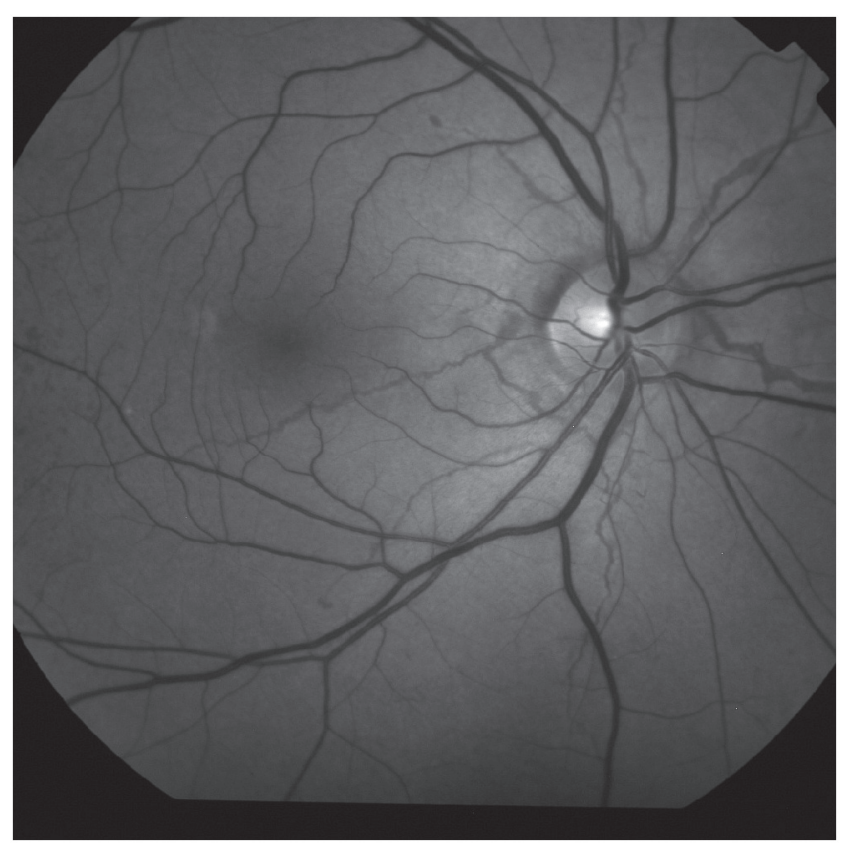

Figure I Red free fundus photo showing typical angioid streaks.
Angioid streaks have a typical appearance as narrow, jagged lines deep to the retina, almost always bilaterally. They radiate out in a cruciate pattern from an area of peripapillary pigment alterations. They may circumferentially ring the peripapillary area as well (Figure 1; Figure 2). Angioid streaks are evident in fundoscopy a few millimetres from the optic disc and rarely occur in the periphery of the posterior pole. Clinical diagnosis is usually straightforward. Angioid streaks have a thickness of $50-500 \mu \mathrm{m}$ and are visible in fundoscopy under the retinal vessels. $^{11,15,17,18}$

The color of angioid streaks depends on the background coloration of the fundus and the degree of the atrophy of the overlying RPE. Thus, angioid streaks are red in light-colored individuals, while in patients who have darker background pigmentation, they are usually medium to dark brown. Angioid streaks become darker as time passes by and at the same time discoloration of RPE occurs. Sometimes angioid streaks are extremely dark and have several bonds between them giving the appearance of a 'spider's web' in the retina. In other occasions a fibrous connective tissue develops around angioid streaks which appear obscure and light-colored. ${ }^{11,17,18}$

In cases where angioid streaks are confined to macula and especially if the foveolar avascular zone is affected, patients develop metamorphopsia and reduced visual acuity. In contrary, if the fovea is unaffected, patients remain

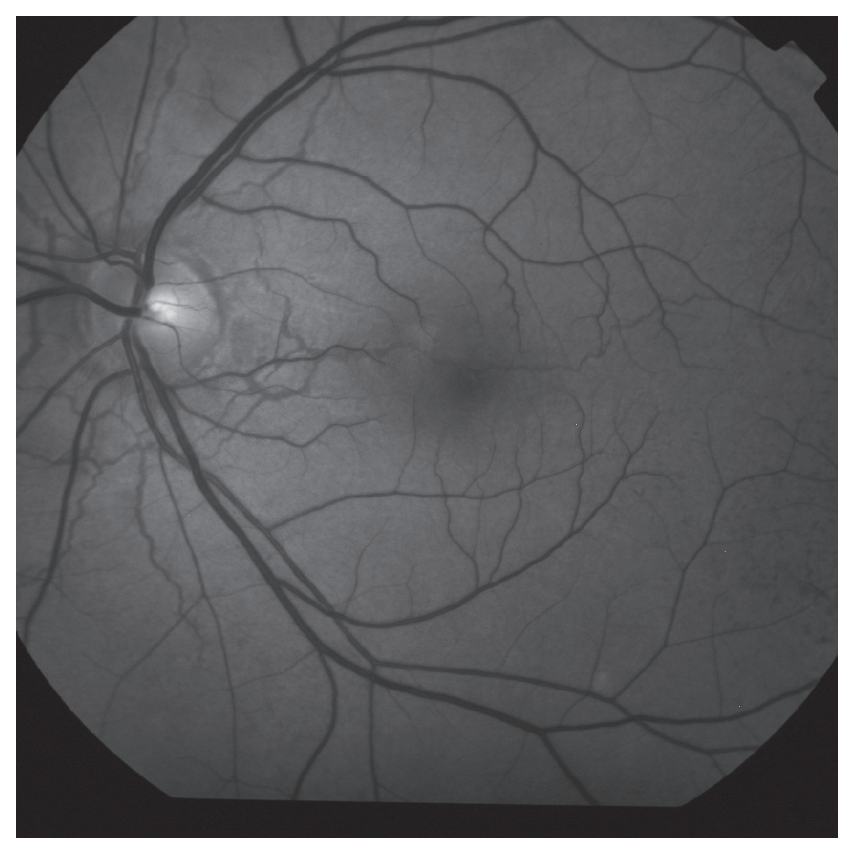

Figure 2 Red free fundus photo showing an angioid streak crossing the macula. 
Table I Systemic conditions associated with angioid streaks

- Hemochromatosis

- Acromegaly

- Diabetes mellitus

- Sickle-cell hemoglobinopathies

- Pseudoxanthoma elasticum

- Acquired hemolytic anaemia

- Hereditary spherocytosis

- Myopia

- Neurofibromatosis

- Paget's disease

- Ehlers-Danlos syndrome

- Sturge-Weber syndrome

- Hyperphosphatemia

asymptomatic and angioid streaks are an accidental finding during a routine ophthalmological investigation.

\section{Fluorescein angiography, indocyanine green angiography}

The photographs taken with the filters of fluorescein angiography before the intravenous administration of the contrast material (fluorescein dye) provide the physician with important information because angioid streaks frequently present the phenomenon of auto-illumination. Also, optic disc drusen which are often associated with angioid streaks show auto-illumination in fruoroangiography. ${ }^{11,19}$

Typically, angioid streaks have a 'window defect' in fluorescein angiography due to atrophy of RPE adjacent to them. Leakage of fluorescein is evident when $\mathrm{CNV}$ is present. The diagnosis of angioid streaks is usually made on the basis of fundoscopy, but intravenous fluorescein angiography can help to delineate the presence of the disease when the ophthalmoscopic appearance is subtle (Figure 3). ${ }^{20}$

Indocyanine Green (ICG) angiography is a useful diagnostic tool for angioid streaks only in the rare case that fundoscopy and fluorescein angiography can not confirm the diagnosis. Such occasions involve the severe lesions of RPE which cause hyperfluorescent lines that are obscure or the development of macular CNV; in these cases ICG angiography demonstrates the neovascular membrane more clearly than fluorescein angiography. ICG angiography shows hyperfluorescent lines with 'pinpoints' over their whole length that are larger and more numerous than those on fluorescein angiography or red-free photography (Figure 4). On the contrary, recently developed angioid streaks become evident only at the late stage of the examination and have

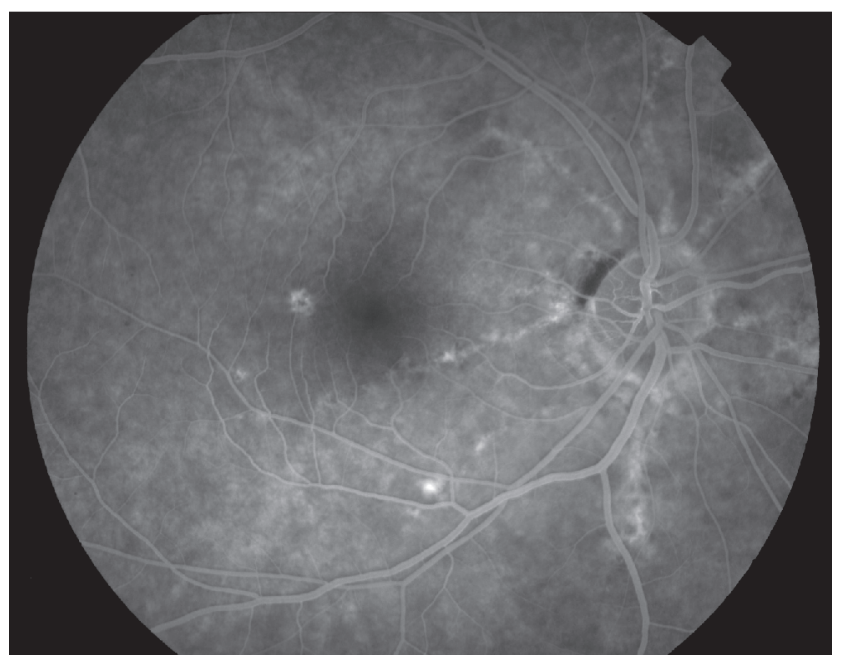

Figure 3 "Window defect" in fluorescein angiography due to atrophy of RPE adjacent to angioid streaks.

the appearance of hypofluorescent linear distortions around optic nerve head or posterior pole. ${ }^{11,18}$

\section{Clinical course, complications}

Patients with angioid streaks are generally asymptomatic, unless the lesions extend towards the foveola or develop complications such as traumatic Bruch's membrane rupture or macular CNV (Figures 5,6).

The increase in length and width of angioid streaks is considered as an expected feature of the disease, but there are no clinical studies determining the rate of their propagation in correlation with time. Increase in length results in lower visual acuity if the angioid streaks spread to the macular region and particularly in the foveolar avascular zone.

Patients with angioid streaks may develop breaks of the Bruch's membrane even after relatively mild head injuries (traumatic dehiscences in Bruch's membrane), since their Bruch's membrane is brittle. ${ }^{11}$ A retrospective study on patients with angioid streaks mentioned that $15 \%$ of those who suffered a head injury developed significant visual impairment. ${ }^{21}$ Traumatic breaks of Bruch's membrane are frequently followed by subretinal hemorrhages which can be easily misinterpreted as CNV. These hemorrhages appear usually next to the angioid streaks and sometimes disseminate into the macula. ${ }^{21,22}$

\section{Choroidal neovascularization}

The commonest and most serious complication of angioid streaks is CNV in the macular region. Such a complication deteriorates dramatically the prognosis of angioid streaks because it is one of the most difficult clinical entities an 


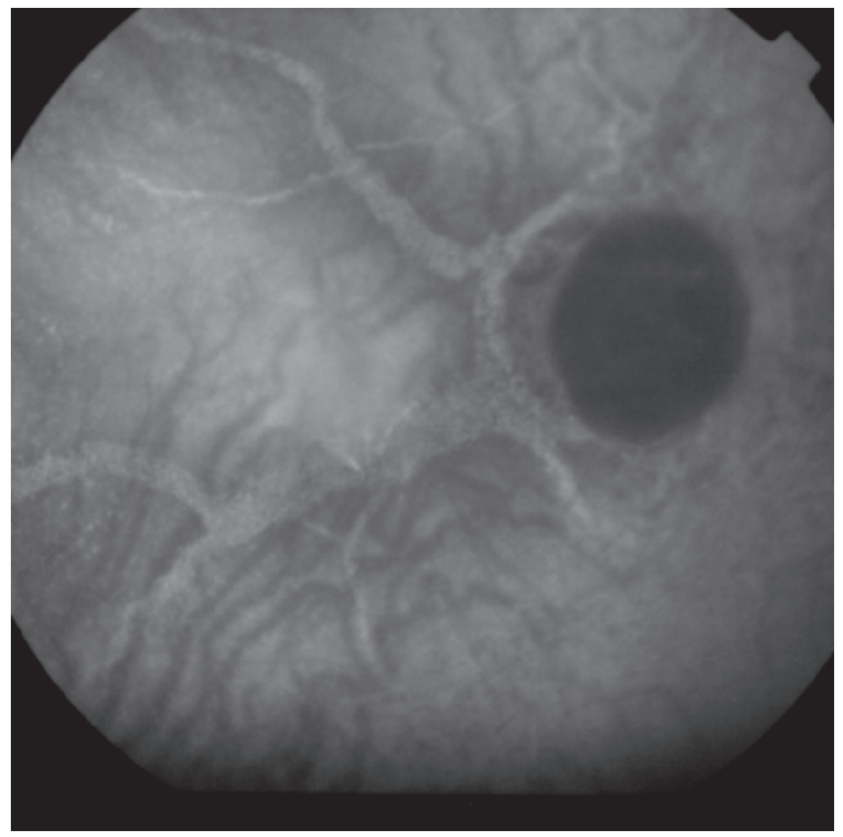

Figure 4 Indocyanine Green angiography of angioid streaks please note the hyperfluorescent lines with 'pinpoints'.

ophthalmologist can encounter. Patients with angioid streaks who develop CNV (Figure 6) are symptomatic and their main symptoms are metamorphopsias and reduction of vision.

Fluorescein angiography confirms the presence of classic $\mathrm{CNV}$ in most cases and helps define the margins of the neovascular membrane, which is typically above or right next to the angioid streaks (Figures 7,8 ). In some occasions it is difficult to determine the borders of the neovascular membrane in fluorescein angiography due to adjacent hemorrhages or RPE lesions. In these cases ICG angiography is an invaluable diagnostic tool.

The incidence of CNV in patients with angioid streaks varies between $72 \%-86 \%$ in numerous studies.

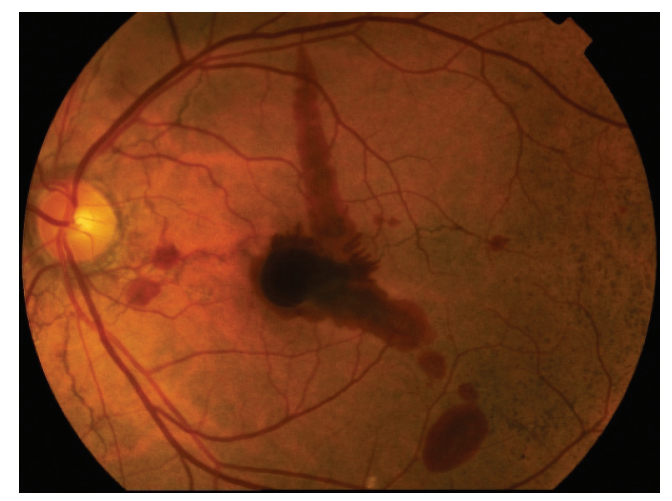

Figure 5 Macular hemorrhage complicating an eye with angioid streaks; note the "peu d'orange" appearance of the fundus temporal to the macula.

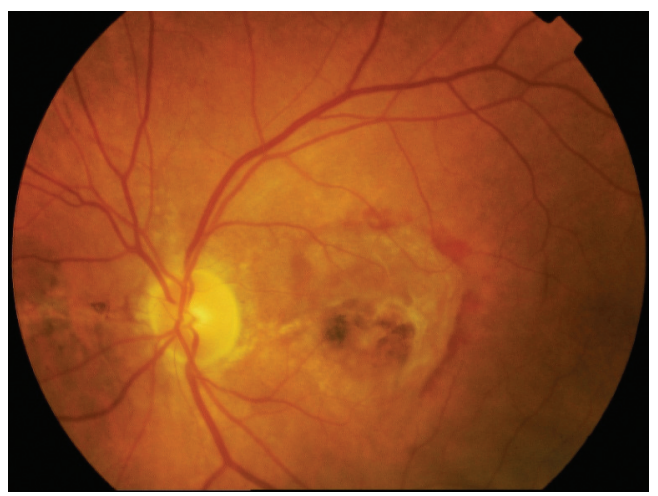

Figure 6 Color fundus photograph in an eye with angioid streaks and choroidal neovascularization.

Commonly, neovascularization involves both eyes, but does not occur simultaneously; there is an interval of roughly 18 months. ${ }^{2,6,11,21,23}$

The risk of developing CNV increases with age. ${ }^{24}$ Other risk factors comprise the width, length and location of the angioid streaks. The wider and longer are the angioid streaks the higher the risk for CNV and especially if the lesions are located in a distance less than one optic disc diameter from the foveola. ${ }^{25,26}$

Angioid streaks associated with pseudoxanthoma elasticum have a relatively high probability of developing macular CNV; ${ }^{24}$ the opposite happens in patients suffering sickle-cell anemia. ${ }^{27,28}$

The standard outcome is poor if CNV in the macular region remains untreated because it leads to further extensive formation of subfoveal scarring of CNV causing severe deterioration of visual acuity. ${ }^{20}$ More than $50 \%$ of such patients eventually become legally blind since their visual acuity is less than $1 / 20 .^{29}$

\section{Treatment \\ Laser photocoagulation}

The incidence of $\mathrm{CNV}$ in patients with angioid streaks varies between $72 \%-86 \%$ in different studies. Normally, neovascularization involves both eyes, but does not occur simultaneously.

The prophylactic therapy of angioid streaks with laser beams in order to avoid the development of CNV has been used before, ${ }^{30}$ but it is no longer recommended and many researchers strongly believe that this kind of intervention can actually induce $\mathrm{CNV} .{ }^{31}$

Photocoagulation with thermal laser was regarded as the only possible therapeutic modality for macular $\mathrm{CNV}$ and consequently was introduced in angioid streaks. Clarkson and 


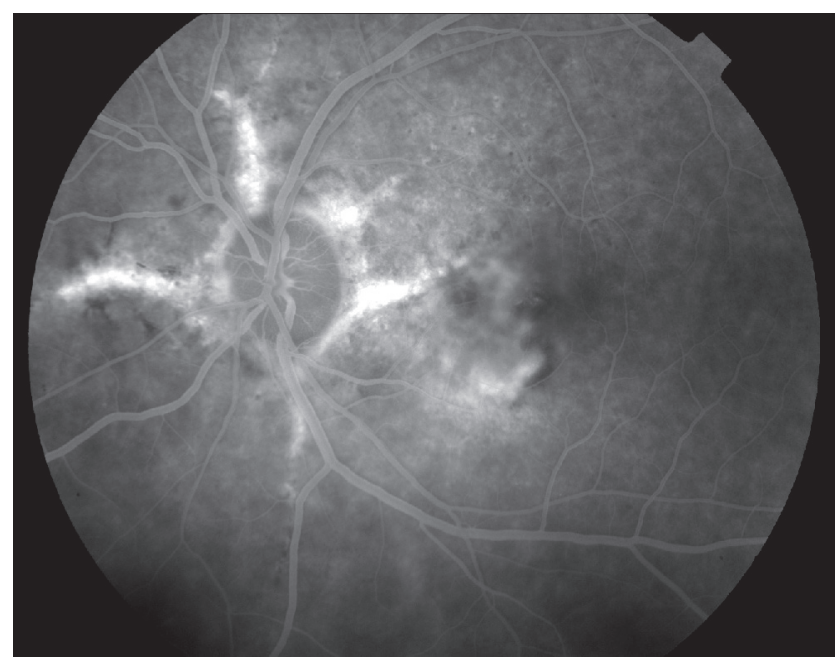

Figure 7 Fluorescein angiography of left eye with angioid streaks complicated by choroidal neovascularization.

colleagues ${ }^{12}$ presented a case series report of six patients with angioid streaks and CNV of the macular region, who were treated with a thermal laser directly targeting the neovascular membrane. Their results were devastating and all patients developed further expansion of the neovascularization causing loss of central vision. At the same time, other small case series reports stated that laser photocoagulation had some encouraging results in neovascularization outside the foveolar region. ${ }^{32-34}$

In 1988, Gelisken and colleagues ${ }^{35}$ presented the results of a study involving 30 eyes with CNV due to angioid streaks. All patients were treated with green argon or krypton laser and the follow-up was two months to 16 years. The authors concluded that the eyes which had extrafoveolar neovascular membranes benefited from the application of thermal laser since they retained a useful vision compared to the eyes that remained untreated. Additionally, they stressed that in cases of subfoveal CNV, no treatment should be applied. Finally, they suggested that no statistically significant difference was observed in using argon and krypton laser, but they preferred the latter.

During the last 20 years, several clinicians drew the same conclusion from these results and thus the dominant contemporary theory is that the efficacy of photocoagulation for macular CNV in angioid streaks is of limited application due to the high percentage of neovascular membrane relapse. ${ }^{36}$

\section{Transpupillary thermotherapy}

Recently, ophthalmologists' interest has switched towards laser treatment with reduced use of energy and such an application is the diode laser using beams of $810 \mathrm{~nm}$ length. Such a laser beam has better penetration through the transparent media of the eye, better action and well-controlled thermal effect causing less absorption by the RPE and deeper penetration in the choriocapillaris. ${ }^{37,38}$

Transpupillary thermotherapy uses a diode laser at a lower threshold that does not cause thermal burn and has been applied for the treatment of macular CNV of any origin. Aras and colleagues ${ }^{37}$ tried this method in patients with subfoveal neovascular membranes in angioid streaks and concluded that it does not seem to affect the course of the disease and at the same time they observed a spreading out of the borders and the leakage of the membrane.

\section{Macular translocation surgery}

This surgical technique was introduced by Machemer and Steinhorst ${ }^{39}$ in 1993. Macular translocation involves moving the neurosensitive retina (macula and varying amounts of adjacent retina) to a new location, away from the ingrowth of the new vessels. This may be accomplished by limited translocation, in which a limited retinal detachment is made and the scleral wall is shortened by imbrication or out-pouching, or there may be a 360-degree retinotomy, with a rotation of the entire retina. This operation is followed by a strabismus surgery. Since the first operation was performed there are several modifications by many vitreoretinal surgeons with encouraging results. ${ }^{40-43}$ However, we should stress that it is a complex, difficult, long-lasting operation which has serious complications (retinal detachment, proliferative vitreoretinopathy, endophthalmitis, etc.) threatening the central and peripheral vision of the patients.

Macular translocation surgery was used in macular CNV in angioid streaks. Roth and colleagues ${ }^{44}$ described a case where they performed a successful lower macular translocation followed by laser photocoagulation in the region of choroidal neovasular membrane in a patient with angioid streaks. The end result was encouraging and other surgeons had similarly good results. ${ }^{45,46}$ It should be mentioned that these encouraging results can not be fully evaluated since the number of patients and the studies involved are of a very small number.

\section{Photodynamic therapy}

Large randomized clinical trials were performed to evaluate the efficacy of photodynamic therapy (PDT) with verteporfin for CNV secondary to age-related macular degeneration (AMD) and pathologic myopia. ${ }^{47-49}$ Since the results of these studies were promising, clinician tried to use PDT in other pathological entities causing CNV. 


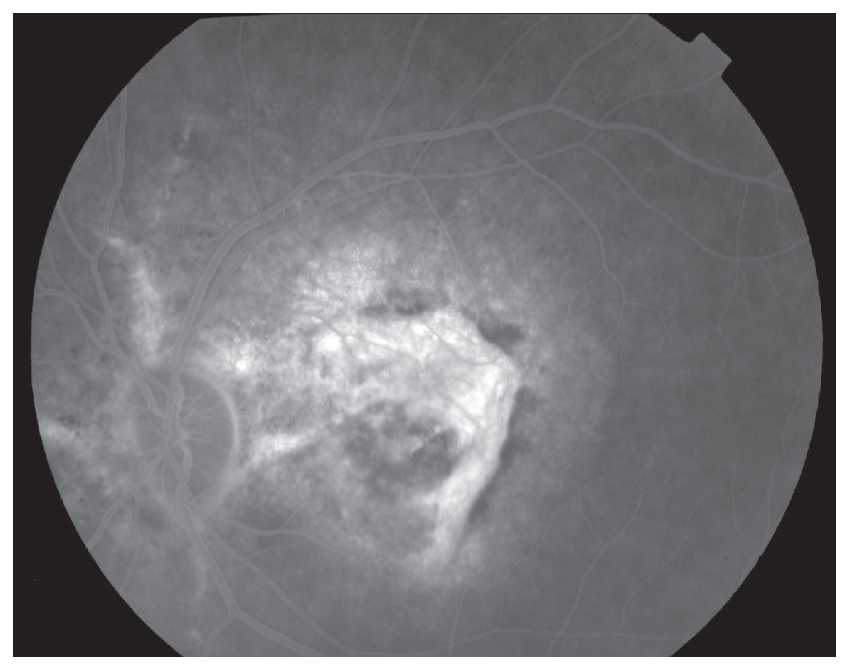

Figure 8 Fluorescein angiography of right eye with angioid streaks complicated by choroidal neovascularization.

In 2000, the Archives of Ophthalmology published the first results of the application of PDT for CNV not caused by macular degeneration. In this study group there was one patient with angioid streaks. ${ }^{50}$ He was a 55 -year-old man who was treated only once with PDT and had a 12-month follow up. During the follow up time there was no further deterioration of his visual acuity, but at the same time the leakage of fluorescein dye from the neovascular membrane remained unaffected.

Two years later, Karacorlu and colleagues ${ }^{51}$ from the 'Istanbul Retina Institute' in Turkey published their results from eight patients with angioid streaks who had PDT. None of the patients developed reduction of the visual acuity and the average improvement of visual acuity was 1.37 lines on the Snellen chart. Three patients had fluorescein leak from the neovascular membrane during their last visit. Based on these results the authors of the article concluded that PDT plays an important role in the management of CNV in angioid streaks, but they stressed that more studies with larger number of patients and longer follow up should be done in order to evaluate accurately the efficiency of PDT in the treatment of macular $\mathrm{CNV}$ in angioid streaks.

A year later, Shaikh and colleagues ${ }^{52}$ presented their results in the same journal. Their study encompassed 11 eyes from nine patients with angioid streaks who had PDT for CNV in the macular region. Nine eyes developed a disciform scar in the place of CNV at the end of follow-up (5-28 months). None of them showed improvement in visual acuity and the vast majority of the patients had deterioration of the vision. The authors point out that one patient with bilateral parafoveal CNV had severe visual worsening on the eye that was treated according to the PDT protocol (repeated every 12 weeks), while the other eye which had PDT with early re-treatments (every six weeks) retained its visual acuity. As a result, they concluded that PDT does not seem to affect the natural course of $\mathrm{CNV}$ in angioid streaks unless the repetition of treatment was applied in shorter intervals. Nonetheless, this publication had the same limitations (small number of patients, short follows up) with the previous one.

Similar results were presented during the same year by Mennel and colleagues ${ }^{53}$ who treated with PDT two patients with $\mathrm{CNV}$ due to angioid streaks: the leakage from the neovascular membrane was greater after the PDT.

In 2004, Menchini and colleagues ${ }^{54}$ published the results of a retrospective multicenter clinical trial from Italy, which involved 40 patients with angioid streaks who developed CNV in the macula and were treated with PDT. Visual acuity reduced in $32 \%$ of patients with subretinal and $50 \%$ of patients with parafoveal neovascular membranes, respectively. CNV had increased in size during the last follow-up visit in almost two thirds of the patients (62\%). Based on these results, the authors drew the conclusion that PDT can be used for decelerating the natural course of macular $\mathrm{CNV}$ in angioid streaks because there are no other efficient therapeutic modalities and also because the side effects of PDT are rare. The number of patients in this study is relatively sufficient to draw safe conclusions, but the study was a retrospective one and the follow-up was very short (five months).

Browning and colleagues ${ }^{55}$ designed a prospective study of 22 patients with angioid streaks who underwent PDT and were followed up for a short period of time (12 months). In this study, the PDT for patients with parafoveal CNV decelerated the course of the disorder. Similar results were presented by Heimann and colleagues ${ }^{56}$ in a retrospective study of 12 patients with a follow up of 12-50 months. According to their results, PDT seems to delay, but not prevent, the development of $\mathrm{CNV}$ in patients having angioid streaks and therefore these results suggest that modifications or combination of PDT with other treatment strategies can provide better results in the future.

Arias and colleagues ${ }^{57}$ reported on PDT in angioid streaks relatively recently. Ten patients (10 eyes) with pseudoxanthoma elasticum had PDT with an average 18-month follow up. The results were appalling since only three patients retained the initial visual acuity, while four patients had dramatic deterioration of visual function (more than six lines on the Snellen chart). Based on their finding, they concluded 
that PDT is not effective in the treatment of macular CNV with the background of angioid streaks.

Ladas and colleagues ${ }^{58}$ evaluated the effectiveness of conventional PDT in a series of 24 eyes of 22 patients with $\mathrm{CNV}$ due to angioid streaks and compared it to the effectiveness of a PDT modification where retreatments were performed earlier (every eight weeks instead of 12).

At the end of the follow-up, final best-corrected visual acuity decreased in 21 of the total 24 eyes and In 19 eyes final best-corrected visual acuity was equal to or less than 20/400. There were not any statistically significant differences in final visual acuity between the two groups and the authors concluded that the functional and the anatomic results of PDT were not satisfactory, even when retreatments were performed earlier than the conventional time of three months.

In conclusion, from all previous studies and case reports it is evident that, despite the initial encouraging results from the application of PDT for the treatment of CNV in the macula, the end results did not fulfill the initial expectations. In addition, several studies present contradictory results and others consider PDT as an adjuvant therapy that does not prevent, but slows down the natural course of $\mathrm{CNV}$.

\section{Antivascular endothelial growth factor treatment}

Anti-vascular endothelial growth factor (VEGF) treatment has resulted in unprecedented visual and anatomic outcomes far outpacing other available treatments for CNV due to AMD. ${ }^{59-61}$ Today physicians and patients can expect visual stabilization in most patients and visual improvement in many, particularly if treatment is begun early in the course of the disease. PDT in combination with anti-VEGF has been also used for the treatment of CNV. ${ }^{62,63}$

Ranibizumab $^{64}$ (Lucentis) is a recombinant humanized immunoglobulin G1 and isotype monoclonal antibody fragment designed for intraocular use which binds to and inhibits the biologic activity of human VEGF A.

Bevacizumab, ${ }^{65}$ is a recombinant humanized full-length antibody that binds to all isoforms of VEGF, similar to ranibizumab which has been offered as an off-label intravitreal application for the treatment of wet AMD.

Wecke and colleagues ${ }^{66}$ reported favorable result in a patient with $\mathrm{CNV}$ due to angioid streaks after intravitreal injection of bevacizumab.

Chang and colleageus ${ }^{67}$ reported their results of intravitreous injection of bevacizumab for $\mathrm{CNV}$ from other causes than AMD and among them 11 patients suffered from angioid streaks. The CNV responded well to bevacizumab injections, however, as the authors stated, in between these eyes there was a high proportion of eyes that had previously undergone PDT so the results may have been biased.

Recently Donati and colleagues ${ }^{68}$ reported the use of intravitreal injection of bevacizumab for $\mathrm{CNV}$ in six eyes of five patients with angioid streaks. The authors concluded that bevacizumab may be useful in the treatment of CNV due to angioid streaks. However, their results may have been compromised by the fact that all eyes had previously undergone PDT or laser photocoagulation.

Schiano-Lomoriello and colleagues ${ }^{69}$ reported two patients with $\mathrm{CNV}$ secondary to angioid streaks who received three intravitreal injections of bevacizumab and followed them for one year. The authors concluded that intravitreal injections of bevacizumab appeared to be an effective and safe treatment for $\mathrm{CNV}$ and resulted in a long-term $\mathrm{CNV}$ inactivation.

The results from 11 and six patients suffering from CNV associated with angioid streaks were reported recently by Neri and colleagues ${ }^{70}$ and Wiegand and colleagues, ${ }^{71}$ respectively. In both studies, intravitreal bevacizumab was found to mildly reduce central foveal thickness and stabilize visual acuity. Both studies concluded that intravitreal bevacizumab may be a promising treatment. Future studies are required to validate their findings.

In conclusion, the visual prognosis in patients with $\mathrm{CNV}$ secondary to angioid streaks, if untreated, is poor and most treatment modalities until recently have failed to limit the devastating impact of CNV in central vision.

However, it is likely that treatment with anti-VEGF, especially in treatment-naive eyes would yield favorable results and this has to be investigated by future studies.

\section{Disclosure}

The authors report no conflicts of interest in this work.

\section{References}

1. Doyne RW. Choroidal and retinal changes. The results of blows on the eyes. Trans Ophthalmol Soc U K. 1889;9:128.

2. Knapp H. On the formation of dark angioid streaks as unusual metamorphosis of retinal hemorrhage. Arch Ophthalmol. 1892;26:289-292.

3. Kofler A. Beitrage zur Kenntnis der angioid Streaks (Knapp). KIin Augenheilkd. 1917;82:134-149.

4. Bock Z. KIinik und Anatomie der gefassahnlichen Streifen im Augenhintergrund. Z Augenheilkd. 1938;95:1-50.

5. Hagedoorn A. Angioid streaks. Arch Ophthalmol. 1939;21:746-774, 935-965.

6. Connor PJ Jr, Juergens JL, Perry HO, Hollenhorst RW, Edwards JE. Pseudoxanthoma elasticum and angioid streaks. A review of 106 cases. Am J Med. 1961;30:537-543. 
7. Dabbs TR, Skjodt K. Prevalence of angioid streaks and other ocular complications of Paget's disease of bone. Br J Ophthalmol. 1990;74:579-582.

8. Gass JD, Clarkson JG. Angioid streaks and disciform macular detachment in Pagets disease (osteitis deformans). Am J Ophthalmol. 1973;75:576-586.

9. Condon PI, Serjeant GR. Ocular findings of elderly cases of homozygous sickle-cell disease in Jamaica. Br J Ophthalmol. 1976;60:361-364.

10. McWilliam RJ. On the histology of angioid streaks. Trans Ophthalmol Soc UK. 1951;71:243-249.

11. Gass JD. Stereoscopic Atlas of Macular Diseases, 3rd edition. St Louis: CV Mosby Co;1987. p. 102-109.

12. Clarkson JG, Altman RD. Angioid streaks. Surv Ophthalmol. 1982;26:235-246.

13. Paton D. Angioid streaks and sickle cell anemia. Arch Ophthalmol. 1959;62:852-858.

14. Klien BA. Angioid streaks: A clinical and histopathologic study. Am J Ophthalmol. 1947;30:955-968.

15. Jampol LM, Acheson R, Eagle RC Jr, Serjeant G, O’Grady R. Calcification of Bruch's membrane in angioid streaks with homozygous sickle cell disease. Arch Ophthalmol. 1987;105:93-98.

16. Federman JL, Tomer TL, Annesley WH. The macula. A Comprehensive Text and Atlas. Baltimore: Williams and Wilkins; 1978. p. 218-231.

17. Guyer D, Gragoudas E, D’Amico DJ. Angioid streaks. Philadelphia, PA: W. B. Saunders and Co.; 1994. p. 852-860.

18. Guyer D, Yannuzzi L, Chang S, Shields JA, Green R. Retina-VitreousMacula. Philadelphia, PA: W. B. Saunders and Co.; 1999.

19. Sawa M, Ober MD, Freund KB, Spaide RF. Fundus autofluorescence in patients with pseudoxanthoma elasticum. Ophthalmology. 2006;113:820, e1-2.

20. Smith JL, Gass JD, Justice J, Jr Fluorescein fundus photography of angioid streaks. Br J Ophthalmol. 1964;48:517-521.

21. Piro P, Scheraga D, Fine S. Angioid streaks: natural history and visual prognosis. In: Fine SL, Owens SL (editor). Management of Retinal Vascular and Macular Disorders. Baltimore, MD: Williams and Wilkins; 1983. p. 136-139.

22. Hagedoorn A. Angioid streaks and traumatic ruptures of Bruch's membrane. Br J Ophthalmol. 1975;59:267.

23. Shields JA, Federman JL, Tomer TL, Annesley WH Jr. Angioid streaks. I. Ophthalmoscopic variations and diagnostic problems. Br J Ophthalmol. 1975;59:257-266.

24. Shilling JS, Blach RK. Prognosis and therapy of angioid streaks. Trans Ophthalmol Soc UK. 1975;95:301-306.

25. Mansour AM, Ansari NH, Shields JA, Annesley WH Jr, Cronin CM, Stock EL. Evolution of angioid streaks. Ophthalmologica. 1993;207:57-61.

26. Mansour AM, Shields JA, Annesley WH Jr, el-Baba F, Tasman W, Tomer TL. Macular degeneration in angioid streaks. Ophthalmologica. 1988;197:36-41.

27. Hamilton AM, Pope FM, Condon PI, et al. Angioid streaks in Jamaican patients with homozygous sickle cell disease. Br J Ophthalmol. 1981;65:341-347.

28. Krill AE, Klien BA, Archer DB. Precursors of angioid streaks. Am J Ophthalmol. 1973;76:875-879.

29. Groenblad E. Color photographs of angioid streaks in the late stages. Acta Ophthalmol (Copenh). 1958;36:472-474.

30. Offret G, Coscas G, Orsoni-Dupont C. [Photo-coagulation of angioid striae after fluoresceinic angiography]. Arch Ophtalmol Rev Gen Ophtalmol. 1970;30:419-422.

31. Verhoeff F. Histological findings in a case with angioid streaks. Br J Ophthalmol. 1948;32:531-544.

32. Singerman LJ, Hatem G. Laser treatment of choroidal neovascular membranes in angioid streaks. Retina. 1981;1:75-83.

33. Meislik J, Neldner K, Reeve EB, Ellis PP. Laser treatment in maculopathy of pseudoxanthoma elasticum. Can J Ophthalmol. 1978;13:210-212.
34. Deutman AF, Kovacs B. Argon laser treatment in complications of angioid streaks. Am J Ophthalmol. 1979;88:12-17.

35. Gelisken O, Hendrikse F, Deutman AF. A long-term follow-up study of laser coagulation of neovascular membranes in angioid streaks. Am J Ophthalmol. 1988;105:299-303.

36. Lim JI, Bressler NM, Marsh MJ, Bressler SB. Laser treatment of choroidal neovascularization in patients with angioid streaks. $\mathrm{Am} \mathrm{J}$ Ophthalmol. 1993;116:414-423.

37. Aras C, Baserer T, Yolar M, et al. Two cases of choroidal neovascularization treated with transpupillary thermotherapy in angioid streaks. Retina. 2004;24:801-803.

38. Newsom RS, McAlister JC, Saeed M, McHugh JD. Transpupillary thermotherapy (TTT) for the treatment of choroidal neovascularisation. Br J Ophthalmol. 2001;85:173-178.

39. Machemer R, Steinhorst UH. Retinal separation, retinotomy, and macular relocation: II. A surgical approach for age-related macular degeneration? Graefes Arch Clin Exp Ophthalmol. 1993;231:635-641.

40. Toth CA, Freedman SF. Macular translocation with 360-degree peripheral retinectomy impact of technique and surgical experience on visual outcomes. Retina. 2001;21:293-303.

41. Toth CA, Lapolice DJ, Banks AD, Stinnett SS. Improvement in near visual function after macular translocation surgery with 360-degree peripheral retinectomy. Graefes Arch Clin Exp Ophthalmol. 2004;242:541-548.

42. Park CH, Toth CA. Macular translocation surgery with 360-degree peripheral retinectomy following ocular photodynamic therapy of choroidal neovascularization. Am J Ophthalmol. 2003;136:830-835.

43. de Juan E Jr, Fujii GY. Limited macular translocation. Eye. 2001;15:413-423.

44. Roth DB, Estafanous M, Lewis H. Macular translocation for subfoveal choroidal neovascularization in angioid streaks. Am J Ophthalmol. 2001;131:390-392.

45. Fujii GY, Humayun MS, Pieramici DJ, Schachat AP, Au Eong KG, de Juan E Jr. Initial experience of inferior limited macular translocation for subfoveal choroidal neovascularization resulting from causes other than age-related macular degeneration. Am J Ophthalmol. 2001;131:90-100

46. Tanaka M, Shimada H, Haruyama M, Lee Z, Nakajima M, Yuzawa M. [Surgical removal of choroidal neovascularization in angioid streaks]. Nippon Ganka Gakkai Zasshi. 2003;107:440-444.

47. TAP Study Group. Photodynamic therapy of subfoveal choroidal neovascularization in age-related macular degeneration with verteporfin: one-year results of 2 randomized clinical trials - TAP report. Treatment of age-related macular degeneration with photodynamic therapy (TAP) Study Group. Arch Ophthalmol. 1999;117:1329-1345.

48. TAP Study Group. Photodynamic therapy of subfoveal choroidal neovascularization in age related macular degeneration with verteporfin: Two-years results of 2 randomized clinical trials -TAP report 2. Arch Ophthalmol. 2001;119:198-207.

49. VIP Study Group. Verteporfin therapy of subfoveal choroidal neovascularization in age-related macular degeneration: Two-years results of a randomized clinical trial including lesions with occult with no classic choroidal neovascularization - report 2. Am J Ophthalmol. 2001;131:541-560.

50. Sickenberg M, Schmidt-Erfurth U, Miller JW, et al. A preliminary study of photodynamic therapy using verteporfin for choroidal neovascularization in pathologic myopia, ocular histoplasmosis syndrome, angioid streaks, and idiopathic causes. Arch Ophthalmol. 2000;118:327-336.

51. Karacorlu M, Karacorlu S, Ozdemir H, Mat C. Photodynamic therapy with verteporfin for choroidal neovascularization in patients with angioid streaks. Am J Ophthalmol. 2002;134:360-366.

52. Shaikh S, Ruby AJ, Williams GA. Photodynamic therapy using verteporfin for choroidal neovascularization in angioid streaks. Am J Ophthalmol. 2003;135:1-6.

53. Mennel S, Schmidt JC, Meyer CH. Therapeutic strategies in choroidal neovascularizations secondary to angioid streaks. Am J Ophthalmol. 2003;136:580-582; author reply 582-583. 
54. Menchini U, Virgili G, Introini U, et al. Outcome of choroidal neovascularization in angioid streaks after photodynamic therapy. Retina. 2004;24:763-771.

55. Browning AC, Chung AK, Ghanchi F, et al. Verteporfin photodynamic therapy of choroidal neovascularization in angioid streaks: one-year results of a prospective case series. Ophthalmology. 2005;112:1227-1231.

56. Heimann H, Gelisken F, Wachtlin J, et al. Photodynamic therapy with verteporfin for choroidal neovascularisation associated with angioid streaks. Graefes Arch Clin Exp Ophthalmol. 2005;243:1115-1123.

57. Arias L, Pujol O, Rubio M, Caminal J. Long-term results of photodynamic therapy for the treatment of choroidal neovascularization secondary to angioid streaks. Graefes Arch Clin Exp Ophthalmol. 2005:1-5.

58. Ladas ID, Georgalas I, Rouvas AA, Gotsis S, Karagiannis DA, Moschos M. Photodynamic therapy with verteporfin of choroidal neovascularization in angioid streaks: conventional versus early retreatment. Eur J Ophthalmol. 2005;15:69-73.

59. Fine HF. Photodynamic therapy in the anti-VEGF era. Br J Ophthalmol. 2007;91:707-708.

60. Brown DM, Regillo CD. Anti-VEGF agents in the treatment of neovascular age-related macular degeneration: applying clinical trial results to the treatment of everyday patients. Am J Ophthalmol. 2007;144:627-637.

61. Pieramici DJ, Rabena MD. Anti-VEGF therapy: comparison of current and future agents. Eye. 2008;22:1330-1336.

62. Costa RA, Jorge R, Calucci D, Melo LA Jr, Cardillo JA, Scott IU. Intravitreal bevacizumab (Avastin) in combination with verteporfin photodynamic therapy for choroidal neovascularization associated with age-related macular degeneration (IBeVe Study). Graefes Arch Clin Exp Ophthalmol. 2007;245:1273-1280.
63. Ahmadieh H, Taei R, Soheilian M, Riazi-Esfahani M, Ahadi H. Single-session photodynamic therapy combined with intravitreal bevacizumab for neovascular age-related macular degeneration. Eur J Ophthalmol. 2008;18:297-300.

64. Gaudreault J, Fei D, Rusit J, Suboc P, Shiu V. Preclinical pharmacokinetics of Ranibizumab (rhuFabV2) after a single intravitreal administration. Invest Ophthalmol Vis Sci. 2005;46:726-33.

65. Avery RL, Pieramici DJ, Rabena MD, Castellarin AA, Nasir MA, Giust MJ. Intravitreal bevacizumab (Avastin) for neovascular age-related macular degeneration. Ophthalmology. 2006;113:363-372 e5.

66. Wecke T, Knop C, Schreiber W, Behrens-Baumann W. [Intraocular injections of bevacizumab in rare indications - two cases.]. Ophthalmologe. 2008;Jul 6 [Epub ahead of print].

67. Chang LK, Spaide RF, Brue C, Freund KB, Klancnik JM Jr, Slakter JS. Bevacizumab treatment for subfoveal choroidal neovascularization from causes other than age-related macular degeneration. Arch Ophthalmol. 2008;126:941-945.

68. Donati MC, Virgili G, Bini A, et al. Intravitreal bevacizumab (Avastin) for choroidal neovascularization in angioid streaks: A case series. Ophthalmologica. 2008;223:24-27.

69. Schiano-Lomoriello D, Parravano MC, Chiaravalloti A, Varano M. Choroidal neovascularization in angioid streaks and pseudoxanthoma elasticum: 1 year follow-up. Eur J Ophthalmol. 2009;19:151-153

70. Neri P, Salvolini S, Mariotti C, Mercanti L, Celani S, Giovannini A. Long-term control of choroidal neovascularization secondary to angioid streaks treated with intravitreal Bevacizumab (Avastin(R)). Br J Ophthalmol. 2008;Oct 29 [Epub ahead of print].

71. Wiegand TW, Rogers AH, McCabe F, Reichel E, Duker JS. Intravitreal bevacizumab (Avastin) treatment of choroidal neovascularization in patients with angioid streaks. Br J Ophthalmol. 2008;Oct 29 [Epub ahead of print]. 
